\title{
Association of MICA-TM and MICB C1 2 A Microsatellite Polymorphisms with Tumor Progression in Patients with Colorectal Cancer
}

\author{
R. Kopp • J. Glas • U. Lau-Werner • E. D. Albert • \\ E. H. Weiss
}

Received: 24 September 2008 / Accepted: 13 March 2009/Published online: 8 April 2009

(C) The Author(s) 2009. This article is published with open access at Springerlink.com

\begin{abstract}
Purpose The major histocompatibility complex class I related A (MICA) and MICB molecules are ligands of NKG2D receptors on natural killer cells, gamma/delta $\mathrm{T}$ cells, and CD8aß T cells that mediate host antitumor immune response. The role of MICA-TM and MICB C1_2_A alleles in patients with colorectal cancer has not yet been investigated.

Methods We have analyzed the MICA-TM and MICB C1_2_A polymorphisms in colorectal cancer patients $(n=$ 79) by polymerase chain reaction amplification, subsequent electrophoresis, and sequencing in comparison to a previously analyzed cohort of healthy controls $(n=306)$. Allele frequencies obtained for MICA-TM and MICB
\end{abstract}

R. Kopp and J. Glas contributed equally to this work and share first authorship.

R. Kopp $(\bowtie) \cdot$ U. Lau-Werner

Department of Surgery, Klinikum Grosshadern,

University of Munich,

Marchioninistr. 15,

81377 Munich, Germany

e-mail: rkopp@med.uni-muenchen.de

J. Glas

Department of Preventive Dentistry and Periodontology,

University of Munich,

Munich, Germany

E. D. Albert

Department of Pediatrics, Laboratory of Immunogenetics,

Munich, Germany

J. Glas $\cdot$ E. H. Weiss

Anthropology and Human Genetics, Department Biology II,

University of Munich,

Munich, Germany
C1_2_A were compared to histopathological data regarding tumor invasion, disease progression, microsatellite instability, and the presence of KRAS mutations (codon 12) and analyzed for possible impact on tumor-related survival $(n=61)$.

Results Allele frequencies of MICA-TM and MICB C1_2_A polymorphisms were not different in patients with colorectal cancer in comparison to normal controls. In colorectal cancer patients, MICA-TM A4 allele was directly and MICA-TM A5 allele was inversely associated with lymph node involvement and advanced UICC stages. Tumor-related survival in colorectal cancer patients was significantly reduced in the presence of the MICA-TM A4 allele $(p=0.015)$. In patients with microsatellite stable tumors, survival was reduced in association with the MICA-TM A4 allele $(p=0.006)$ and MICA-TM A9 allele $(p=0.034)$, but increased in patients showing the MICA-TM A5 allele $(p=0.042)$.

Conclusions Specific MICA-TM alleles seem to influence tumor progression and midterm survival of patients with colorectal cancer, indicating an important role of host innate immune predisposition involving NKG2D mediated antitumor response.

Keywords $\mathrm{MHC} \cdot \mathrm{MICA} \cdot \mathrm{MICB} \cdot$

microsatellite polymorphism $\cdot$ colorectal cancer .

tumor progression

$\begin{array}{ll}\text { Abbreviations } \\ \text { UICC } & \text { Union internationale contre le cancer } \\ \text { MHC } & \text { Major histocompatibility complex } \\ \text { SD } & \text { Standard deviation } \\ \text { HR } & \text { Hazard ratio } \\ \text { CI } & \text { Confidence interval }\end{array}$




\section{Introduction}

The major histocompatibility complex class I chain related A (MICA) and MICB molecules are ligands of NKG2D receptors on natural killer (NK) cells, gamma/delta $\mathrm{T}$ cells, NKT cells, and CD8aß $\mathrm{T}$ cells, and mediate antitumor immune responses by stimulating innate and adaptive immune surveillance [1-3]. Several polymorphisms have been reported for MICA and MICB coding and noncoding sequences, located within the $\mathrm{MHC}$ class I region close to the tumor necrosis factor gene [4, 5]. The MICA-TM microsatellite polymorphism is present in exon 5 with eight alleles (A4, A5, A5.1, A6, A7, A8, A9, and A10), while the MICB gene contains a microsatellite polymorphism named C1_2_A in intron 1 comprising 16 alleles [6, 7]. Different MICA molecules were reported to vary in their affinities to soluble NKG2D receptors, which may influence antitumor immune responses [5, 8]. Recent studies have shown increased serum levels of soluble MICA molecules in patients with various malignancies with a correlation to advanced tumor stages [9]. Circulating tumor-derived soluble MICA molecules induce downregulation of NKG2D receptors on natural killer cells and thereby decrease responsiveness of tumor-antigen-specific effector $\mathrm{T}$ cells [10]. The mechanism of $\mathrm{T}$ and $\mathrm{NK}$ cell silencing by down regulation of NKGD cells induced by soluble ligands or chronic exposure to cell surface bound ligands may represent an important mechanism for tumor cells to escape host antitumor immune responses. Some reports have indicated associations of specific MICA alleles with epithelial tumors of the nasopharynx and gastric mucosa, with hematopoetic neoplasia and with chronic inflammatory and autoimmune disorders [11-15]. The allele and genotype frequencies of MICA-TM and MICB C1_2_A microsatellite polymorphisms in patients with colorectal cancer and a possible immunogenetic predisposition for the development of colorectal cancer or tumor progression have not yet been investigated. We have therefore analyzed the MICA-TM and MICB C1_2_A polymorphisms in samples of normal colon mucosa and tumor tissue from colorectal cancer patients in comparison to a cohort of healthy controls and investigated possible correlations to tumor characteristics and disease progression.

\section{Methods \\ Patients and Controls}

Seventy-nine patients with colorectal cancer were analyzed. The patients had been treated between Jan. 1998 and Dec. 2002 according to the principles of oncologic surgery, and tumors were classified according to TNM/UICC criteria following histopathological examination. Mean age was $67.4 \pm 10.9$ years (range, $34-88$ years), $52.5 \%$ of the patients were male and $47.5 \%$ female. Sixty-eight patients had sporadic colorectal cancer. Patients with evidence for polyposis cancer syndromes were excluded from the study. Eleven patients with clinical evidence for hereditary nonpolyposis colon cancer according to Bethesda criteria were analyzed separately for microsatellite instability to investigate a possible correlation of the DNA replication error pathway with alterations in host antitumor immunity [16]. Primary tumors were localized in the colon $(n=54)$ and rectum $(n=25)$. Twenty-three patients had UICC stage IV tumors with distant metastasis localized in the liver $(n=12)$, lungs $(n=6)$, peritoneum $(n=4)$, or at multiple sites $(n=4)$. Results of lymph node involvement (N-classification) were included in the study, when at least 12 lymph nodes were removed and histopathologically examined. Frequencies of MICA-TM and MICB C1_2_A polymorphisms in colorectal cancer patients were compared to a previously analyzed cohort of healthy controls $(n=306)$ [17]. The study was approved by the local ethics committee, and patients' informed consent was obtained.

Postoperative follow-up was performed according to the recommendations of the Munich cancer center and prospectively documented in an institutional data base. Followup intervals were initially every 6 months for 2 years, then yearly for up to the sixth year and at 2-year intervals for up to 10 years, including clinical examination, determination of carcinoembryonic antigen levels, upper abdomen sonography, abdominal CT scan, and total colonoscopy. Rectoscopy was performed in patients with rectal cancer or with an anastomosis below $12 \mathrm{~cm}$ as measured from the anocutanous line. Only patients with complete histopathological examination according to the TNM/UICC criteria and prospective follow-up were considered for analysis of survival times. Mean follow-up \pm SD was $56.2 \pm 36.3$ months (range, 1-106 months).

\section{MICA-TM and MICB C1_2_A Genotyping}

MICA-TM and MICB C1_2_A polymorphisms were genotyped in genomic DNA isolated from normal colonic mucosa and colorectal tumor tissue, respectively [18]. Allele frequencies of MICA-TM and MICB C1_2_A polymorphisms were compared to a group of 306 healthy control persons, analyzed previously (mean age, $62.8 \pm 11.8$ years; sampling period Jan. 1997 to Dec. 2000) [17]. The MICA-TM polymorphism was analyzed by polymerase chain reaction (PCR) amplification with the primers 5'-CAGAGTCAT TGGCAGACA-3' (5'-Fam-labeled) and 5'-TTCTTCTTA CAACAACGGAC-3'. The PCR products were separated by electrophoresis on denaturating $6 \% \quad 0.3-\mathrm{mm}$ polyacrylamide gels in the ALFexpress sequencer (Amersham 
Pharmacia, Uppsala, Sweden). The segregation of the MICA-TM alleles was controlled in 20 HLA-A, B, DRtyped families. Sequencing confirmed the allele size determined. As internal standards, a 73-bp PCR product from the transforming growth factor receptor II and ALFexpress Sizer 150 for MICB C1_2_A were used, respectively.

MICB C1_2_A alleles of interest, including the gold standards, were sequenced either directly as PCR products or after subcloning into the vector pCR2.1 (Invitrogen). For sequence analysis of MICB C1_2_A microsatellite, alleles were amplified with the primers 5'-CCATAGTGTTTTCC ATTGCAGGC-3' and 5'-AGCCATGAGAAGCTAT GTGGGG-3'. The PCR products were purified using a QIA Quick PCR Purification Kit (Qiagen, Hilden, Germany) and were sequenced using the ABI PRISM ${ }^{\mathrm{TM}}$ dye terminator cycle sequencing kit on an ABI 373 DNA sequencer. The raw data were analyzed by the ABI Sequence Analysis program.

Screening for Tumor Microsatellite Instability and KRAS Oncogene Mutations

Analysis of tumor microsatellite instability (MIN) was performed using the microsatellite markers BAT26, BAT40, TGFBR2 $(\mathrm{A})_{10}, B A X(\mathrm{G})_{8}$, and the dinucleotide repeat $M F D 15$ (D17S250), with modifications according to the meeting report of the National Cancer Institute Workshop on microsatellite instability [16]. Tumors exhibiting instability at $0-1$ loci analyzed were considered as presenting low $\mathrm{MIN}$ and at $\geq 2$ loci as high microsatellite instability (MIN-h).

Tumor DNA was screened for KRAS mutations in codon 12 (glycine, GGT) by primer-mediated restriction fragment length polymorphism (RFLP) analysis. The primers used were ACTGAATATAAACTTGTGGTAGTTGGACCT and TCATGAAAATGGTCAGAGAA, the underlined base within the forward primer introduces a $B s t \mathrm{~N}$ I restriction site in the amplified wild-type sequence. The colon carcinoma cell line SW480 carrying a homozygous Val mutation at codon 12 was used as a positive control for RFLP analysis. Additionally, all tumor DNA samples displaying mutated $K R A S$ sequences at codon 12 in RFLP analysis were further analyzed by sequencing in order to confirm to results of RFLP analysis and to determine which mutation was present. For sequence analysis, a 288-bp amplificate was generated using the primers ACTGGTGGAGTATTTGATAG and ACTCATGAAAATGGTCAGAG.

\section{Statistical Analysis}

Haplotype gene frequencies were determined by gene counting assuming homozygosity, if at a given locus only one allele could be identified. Correlations to histopathological parameters were performed comparing MICA-TM and
MICB C1_2_A alleles with tumor invasion, lymph node involvement, presence of distant metastasis, and UICC stages. Statistical significance for the two-point associations was tested by Chi-square calculation in the $2 \times 2$ table and Pearson's coefficient, Fisher's exact test (two-sided) or phi coefficient was used, when appropriate. Survival times were calculated by Kaplan-Meier curves, and the log rank test was used for statistical analysis and comparison of different variables. For multivariate analysis, Cox regression analysis was performed using the Wald test for comparison of variables. A $p$ value of less than 0.05 was used to indicate statistical significance. Statistical analysis was performed using the SPSS statistical software (SPSS version 11.5).

\section{Results}

MICA-TM and MICB C1_2_A Allele Frequencies

Allele frequencies of MICA-TM and MICB C1_2_A in colorectal cancer patients did not differ compared to a cohort of healthy control individuals (Table I). Homozygosity was most frequently observed in colorectal cancer

Table I Allele Frequencies (in \%) of Microsatellites MICA-TM and MICB C1_2_A in Colorectal Cancer Patients and Control Persons

\begin{tabular}{|c|c|c|}
\hline & Colorectal cancer patients $(n=79)$ & Controls $(n=306)$ \\
\hline \multicolumn{3}{|c|}{ MICA-TM allele } \\
\hline A4 & 11.9 & 11.7 \\
\hline A5 & 10.6 & 13.6 \\
\hline A5.1 & 43.1 & 37.0 \\
\hline A6 & 21.9 & 22.4 \\
\hline A9 & 12.5 & 15.3 \\
\hline \multicolumn{3}{|c|}{ MICB C1_2_A allele } \\
\hline CA14 & 16.6 & 18.5 \\
\hline CA15 & 19.2 & 10.5 \\
\hline CA16 & n.d. & 0.2 \\
\hline CA17 & 11.4 & 20.3 \\
\hline CA18 & 8.3 & 7.2 \\
\hline CA19 & 3.1 & 1.1 \\
\hline $\mathrm{CA} 20$ & 3.7 & 4.1 \\
\hline CA21 & 8.0 & 8.9 \\
\hline $\mathrm{CA} 22$ & 4.3 & 7.2 \\
\hline $\mathrm{CA} 23$ & 5.6 & 5.9 \\
\hline $\mathrm{CA} 24$ & 14.8 & 10.9 \\
\hline $\mathrm{CA} 25$ & 4.8 & 3.9 \\
\hline CA26 & n.d. & 0.8 \\
\hline CA27 & n.d. & 0.5 \\
\hline
\end{tabular}

Allele frequencies of control persons were reported in [18] n.d. not detected in our patients' cohort 
Table II Comparison of MICA-TM Allele Frequencies with TumorAssociated Clinicopathological Parameters

\begin{tabular}{|c|c|c|c|c|c|}
\hline \multirow[t]{2}{*}{ Tumor classification } & \multicolumn{5}{|c|}{ MICA-TM allele } \\
\hline & A4 & A5 & A5.1 & A6 & A9 \\
\hline \multicolumn{6}{|l|}{ Tumor invasion } \\
\hline $\mathrm{T} 1 / 2$ & $3 / 17$ & $3 / 17$ & $12 / 17$ & $7 / 17$ & $3 / 17$ \\
\hline $\mathrm{T} 3 / 4$ & $11 / 44$ & $8 / 44$ & $32 / 44$ & $18 / 44$ & $11 / 44$ \\
\hline \multicolumn{6}{|c|}{ Lymph node involvement } \\
\hline No & $9 / 51$ & $11 / 51$ & $39 / 51$ & $20 / 51$ & $11 / 51$ \\
\hline $\mathrm{N} 1-3$ & $5 / 10$ & $0 / 10^{\mathrm{a}}$ & $6 / 10$ & $5 / 10$ & $3 / 10$ \\
\hline \multicolumn{6}{|l|}{ Distant metastasis } \\
\hline M0 & $8 / 47$ & $12 / 47$ & $35 / 47$ & $17 / 47$ & $11 / 47$ \\
\hline M1 & $10 / 23^{b}$ & $1 / 23^{\mathrm{c}}$ & $14 / 23$ & $11 / 23$ & $3 / 23$ \\
\hline \multicolumn{6}{|l|}{ UICC stages } \\
\hline UICC I/II & $4 / 30$ & $10 / 30$ & $22 / 30$ & $11 / 30$ & $5 / 30$ \\
\hline UICC III/IV & $14 / 39$ & $2 / 39^{d}$ & $26 / 39$ & $17 / 39$ & $9 / 39$ \\
\hline
\end{tabular}

${ }^{\mathrm{a}} p<0.05$

${ }^{\mathrm{b}} p<0.023$

${ }^{\mathrm{c}} p<0.048$

d $p<0.02$ patients for the MICA-TM A5.1 allele $(n=13 ; 16.4 \%$ of all patients) and for the MICB C1_2_A CA15 allele $(n=4$; $5.1 \%$ of all patients). Nonsignificant trends were observed in our cohort regarding an increased MICB C1_2_A CA15 allele frequency $(19.2 \%$ vs $10.5 \%)$ and a reduced CA17 allele frequency $(11.4 \%$ vs $20.3 \%)$ in comparison to the control group.

\section{Association of MICA-TM and MICB C1_2_A Alleles} with Tumor-Associated Variables

MICA-TM and MICB C1_2_A alleles were investigated for possible correlation to various tumor-associated variables, including tumor invasion, lymph node involvement, presence of distant metastasis, UICC stages, microsatellite instability, and detection of KRAS mutations (codon 12). As shown in Table II, the MICA-TM A4 allele was associated with the presence of distant metastasis $(p=0.023)$. The presence of the MICA-TM A5 allele showed an inverse association to lymph node involvement $(p=0.015)$, presence of distant metastasis $(p=0.048)$, and advanced UICC stages $(p=0.003)$. The analysis of MICB C1_2_A alleles showed an association of the CA14 allele with the presence of distant metastasis $(p=0.045)$ and of the CA21 allele with advanced UICC stages $(p=0.047)$.
Table III MICA-TM and MICB C1_2_A Polymorphisms in Colorectal Cancer Patients with Regard to Tumor Microsatellite Stability or KRAS Codon 12 Mutations
Microsatellite instability (MIN) was defined as altered lengths of PCR products typing five defined mono- and dinucleotide repeat markers. Tumor MIN was considered when at least one repeat locus showed altered length and high microsatellite instability (MIN-h) when two or more microsatellite markers showed tumor DNA replication errors. For analysis, only MICATM and MICB C1_2_A allele frequencies $>5 \%$ were considered

$* p=0.047$

\begin{tabular}{|c|c|c|c|}
\hline \multirow{2}{*}{$\begin{array}{l}\text { MICA-TM/MICB C1_2_A } \\
\text { Allele frequencies }\end{array}$} & \multicolumn{3}{|c|}{ Tumor-related parameters } \\
\hline & $\operatorname{MIN}(n=17)$ & MIN-h $(n=10)$ & $K R A S$ mutations $(n=17)$ \\
\hline \multicolumn{4}{|l|}{ MICA-TM allele } \\
\hline A4 & $6 / 21$ & $4 / 21$ & $4 / 21$ \\
\hline A5 & $3 / 14$ & $3 / 14$ & $3 / 14$ \\
\hline A5.1 & $10 / 56$ & $7 / 56$ & $9 / 56$ \\
\hline A6 & $6 / 32$ & $3 / 32$ & $9 / 32$ \\
\hline A9 & $4 / 16$ & $2 / 16$ & $5 / 16$ \\
\hline \multicolumn{4}{|l|}{ MICB C1_2_A allele } \\
\hline CA14 & $7 / 24$ & $3 / 24$ & $3 / 24$ \\
\hline CA15 & $4 / 28$ & $3 / 28$ & $4 / 28$ \\
\hline CA16 & n.d. & n.d. & n.d. \\
\hline CA17 & $2 / 17$ & $1 / 17$ & $3 / 17$ \\
\hline CA18 & $2 / 11$ & $1 / 11$ & $3 / 11$ \\
\hline CA19 & $1 / 5$ & $1 / 5$ & $1 / 5$ \\
\hline $\mathrm{CA} 20$ & $1 / 6$ & $0 / 6$ & $1 / 6$ \\
\hline $\mathrm{CA} 21$ & $5 / 13$ & $4 / 13^{*}$ & $4 / 13$ \\
\hline $\mathrm{CA} 22$ & $2 / 7$ & $1 / 7$ & $3 / 7$ \\
\hline CA23 & $1 / 9$ & $0 / 9$ & $4 / 9$ \\
\hline $\mathrm{CA} 24$ & $4 / 24$ & $4 / 24$ & $4 / 24$ \\
\hline $\mathrm{CA} 25$ & $1 / 6$ & $0 / 6$ & $3 / 6$ \\
\hline CA26 & n.d. & n.d. & n.d. \\
\hline $\mathrm{CA} 27$ & n.d. & n.d. & n.d. \\
\hline
\end{tabular}


MICA-TM and MICB C1_2_A Allele Distribution, Microsatellite Instability, and KRAS Mutations

A trend for an increased frequency of the MICB C1_2_A CA21 allele was observed in patients with colorectal tumors showing high microsatellite instability as defined by different lengths of PCR products in more than two markers ( $p=$ 0.047; Table III). Mutations in the KRAS oncogene were detected in 17 colorectal cancer samples (20.9\%). The KRAS codon 12 mutation in tumor DNA samples were determined by sequencing the PCR-generated fragment, and the following mutations (12C: $n=3 ; 12 \mathrm{D}: \quad n=4 ; 12 \mathrm{~V}: n=7 ; 12 \mathrm{~S}: n=$ 2) were detected. No correlation of MICA-TM alleles with the presence of KRAS mutations was seen in the investigated colorectal cancer patients. For MICB C1_2_A alleles, only a trend toward an association with $K R A \bar{S}$ mutations was observed for the CA 23 allele $(p=0.087)$.
Analysis of Survival Times

Overall survival was analyzed in 61 patients with sporadic colorectal carcinomas, followed and documented prospectively in an institutional data base. Tumor-related postoperative survival was $86.0 \pm 4.4$ months for patients following complete tumor resection (R0-status; $n=45)$ and $29.8 \pm 8.4$ months for patients with tumor infiltrated resection margins or remaining distant metastasis $(n=25$; $p<0.001)$. Survival in the study cohort was related to classical parameters of tumor progression like lymph node involvement $(p=0.005)$ and UICC stages $(p=0.001)$ according to univariate analysis, as shown in Table IV. Further analysis indicated significantly shorter survival times in patients positive for the MICA-TM A4 allele (negative vs positive, 80.6 vs 51.9 months; $p=0.015$, Fig. 1). Estimated 5-year survival times were $75 \%$ and
Table IV Survival of Colorectal Cancer Patients
Univariate analysis of tumorrelated survival times of patients with indicated clinicopathological parameters and selected MICA-TM (A4, A5, A5.1, A9) and MICB C1_2_A (CA24) alleles in patients with colorectal cancer $(n=61)$. Kaplan-Meier analysis and the log rank test were used for comparisons and statistical evaluation

\begin{tabular}{|c|c|c|c|}
\hline Tumor-related parameters & $\begin{array}{l}\text { Survival times } \\
\text { (mean } \pm \mathrm{SD} \text {; months) }\end{array}$ & $\begin{array}{l}\text { (95\% Confidence } \\
\text { interval) }\end{array}$ & $p$ value \\
\hline \multicolumn{4}{|l|}{ Tumor invasion } \\
\hline $\begin{array}{l}\mathrm{T} 1 / 2(n=13) \\
\mathrm{T} 3 / 4(n=48)\end{array}$ & $\begin{array}{l}85.0 \pm 9.6 \\
69.0 \pm 6.0\end{array}$ & $\begin{array}{l}(66.2-103.9) \\
(57.1-80.8)\end{array}$ & 0.113 \\
\hline \multicolumn{4}{|l|}{ Lymph node involvement } \\
\hline $\begin{array}{l}\text { N0 }(n=34) \\
\text { N1 }(n=18) \\
\text { N2 }(n=9)\end{array}$ & $\begin{array}{l}88.8 \pm 5.4 \\
65.3 \pm 8.9 \\
25.9 \pm 5.2\end{array}$ & $\begin{array}{l}(78.1-99.4) \\
(47.7-82.8) \\
(6.9-44.9)\end{array}$ & 0.005 \\
\hline \multicolumn{4}{|l|}{ UICC stages } \\
\hline UICC I/II $(n=30)$ & $93.9 \pm 4.8$ & $(84.4-103.4)$ & \\
\hline UICC III/IV $(n=31)$ & $52.7 \pm 7.3$ & $(38.3-67.0)$ & $<0.001$ \\
\hline \multicolumn{4}{|l|}{ A4 } \\
\hline No $(n=47)$ & $80.6 \pm 5.6$ & $(69.7-91.6)$ & \\
\hline Yes $(n=14)$ & $51.9 \pm 10.9$ & $(30.5-73.2)$ & 0.015 \\
\hline \multicolumn{4}{|l|}{ A5 } \\
\hline No $(n=47)$ & $56.0 \pm 6.1$ & $(56.0-80.2)$ & \\
\hline Yes $(n=14)$ & $87.4 \pm 6.3$ & $(75.0-99.7)$ & 0.074 \\
\hline \multicolumn{4}{|l|}{ A5.1 } \\
\hline No $(n=19)$ & $65.2 \pm 9.8$ & $(45.9-84.5)$ & \\
\hline Yes $(n=42)$ & $75.2 \pm 5.7$ & $(63.9-86.6)$ & 0.257 \\
\hline \multicolumn{4}{|l|}{ A9 } \\
\hline No $(n=48)$ & $75.9 \pm 5.5$ & $(65.0-86.8)$ & \\
\hline Yes $(n=13)$ & $59.5 \pm 10.6$ & $(38.7-80.3)$ & 0.106 \\
\hline \multicolumn{4}{|l|}{$\mathrm{CA} 24$} \\
\hline No $(n=42)$ & $66.7 \pm 6.1$ & $(54.7-78.7)$ & \\
\hline Yes $(n=19)$ & $84.3 \pm 8.6$ & $(67.4-101.3)$ & 0.108 \\
\hline \multicolumn{4}{|c|}{ Microsatellite instability ( $\geq 1$ marker) } \\
\hline No $(n=54)$ & $71.7 \pm 5.7$ & $(60.4-83.0)$ & \\
\hline Yes $(n=7)$ & $82.2 \pm 9.5$ & $(63.6-100.9)$ & 0.410 \\
\hline \multicolumn{4}{|l|}{$K R A S$ codon 12 mutations } \\
\hline No $(n=44)$ & $78.7 \pm 6.0$ & $(66.9-90.4)$ & \\
\hline Yes $(n=17)$ & $58.7 \pm 9.5$ & $(40.0-77.5)$ & 0.093 \\
\hline
\end{tabular}




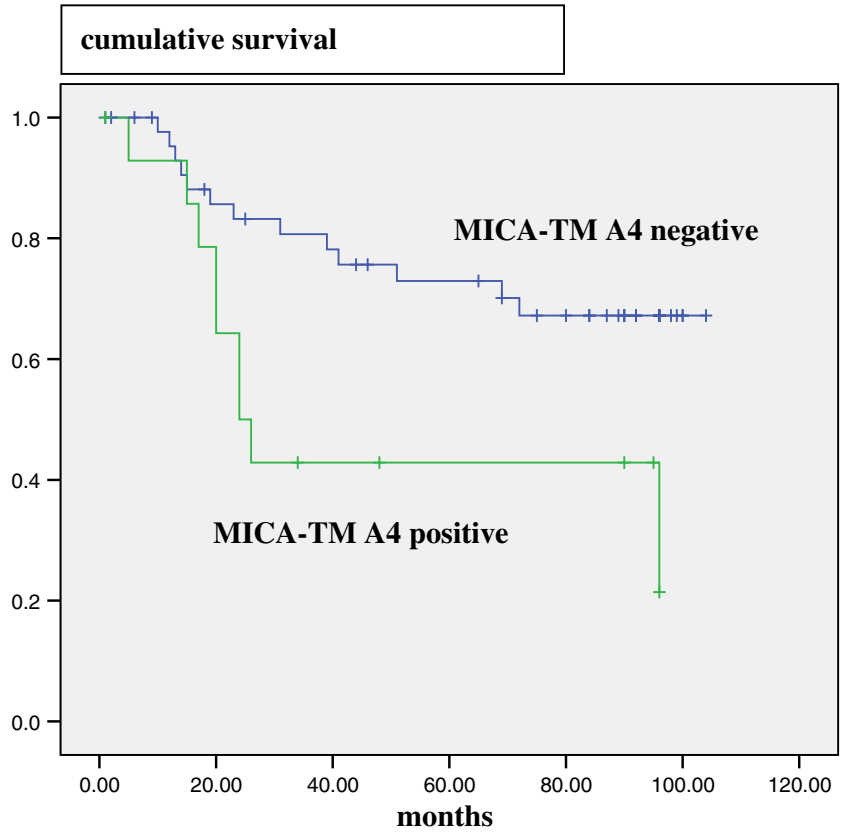

Fig. 1 Survival analysis in relation to MICA-TM A4 allele haplotype. Kaplan-Meier analysis of tumor-related survival times in association with MICA-TM A4 allele in patients with colorectal cancer. Short vertical lines indicate censored observations for comparison of patients without $(n=46)$ and with MICA-TM A4 allele $(n=15, p=0.015)$

43\% for MICA-TM A4 negative and positive patients, respectively. Multivariate analysis using the Cox regression model after exclusion of the variable metastatic disease indicated that presence of MICA-TM A4 allele (HR, 2.71; $95 \%$ CI, $1.13-6.49 ; p=0.025)$ and the tumor-related nodal status (HR, 3.99; 95\% CI, 1.61-9.86; $p=0.003$ ) were independent prognostic variables.

Survival Analysis in Microsatellite Stable Tumors

We have further analyzed survival times in patients with microsatellite stable tumors $(n=54)$. As shown in Fig. 2, prognostic relevance of MICA-TM A4 was even more evident in microsatellite stable tumors $(p=0.006)$ in comparison to the other known prognostic variables such as lymph node involvement $(p=0.001)$ and UICC classification $(p<0.001$, Table IV). In addition, MICA-TM A9 was associated with reduced survival times $(p=0.034)$ in microsatellite stable colorectal cancer patients, while the MICATM A5 was inversely associated with a better prognosis ( $p=0.042$ ), providing evidence for a tumor suppressive effect of the MICA-TM A5 allele (Table V). Further combined analysis of colorectal cancer patients with MICA-TM alleles positive for either A4 or A9 vs patients negative for both A4 and A9 alleles had markedly reduced survival times, as shown in Fig. $3(p<0.001)$, with an estimated 5-year survival of $36 \%$ vs $85 \%$, respectively.
Multivariate analysis by Cox regression with inclusion of the variables MICA-TM A4, A5, A9, lymph node involvement, UICC stages, metastatic disease, and MICA-TM A4 or A9 positive indicated that metastatic disease (HR, 4.43; 95\% CI, 1.66-11.81; $p=0.003$ ), lymph node involvement (HR, 3.27; 95\% CI, 1.14-9.30; $p=0.026$ ) and MICA-TM A4 or A9 positive (HR, 4.02; 95\% CI, 1.29-12.56; $p=0.016$ ) were of independent prognostic relevance in patients with microsatellite stable colorectal tumors.

\section{Conclusions}

The NK group 2, member D -NKG2D protein, is an activating cell surface receptor expressed on NK cells and on some T-cell subsets $[19,20]$. Ligands of human NKG2D include MICA, MICB, UL-16-binding proteins, and Letal and are expressed on several tumors, especially on epithelium-derived cancer cells [4]. Ligand binding of MICA and MICB to the NKG2D receptor mediates innate antitumor response by stimulation of NK cells and gamma delta $\mathrm{T}$ cells and may modulate CD8aß T-cell responses [21, 22]. It was shown that tumor cells expressing high levels of MICA and NKG2D ligands were rejected by NK cells and CD8 alpha/ beta $\mathrm{T}$ cells and stimulated antitumor activity in a mouse model $[23,24]$. Analysis of the structure of the NKG2D-

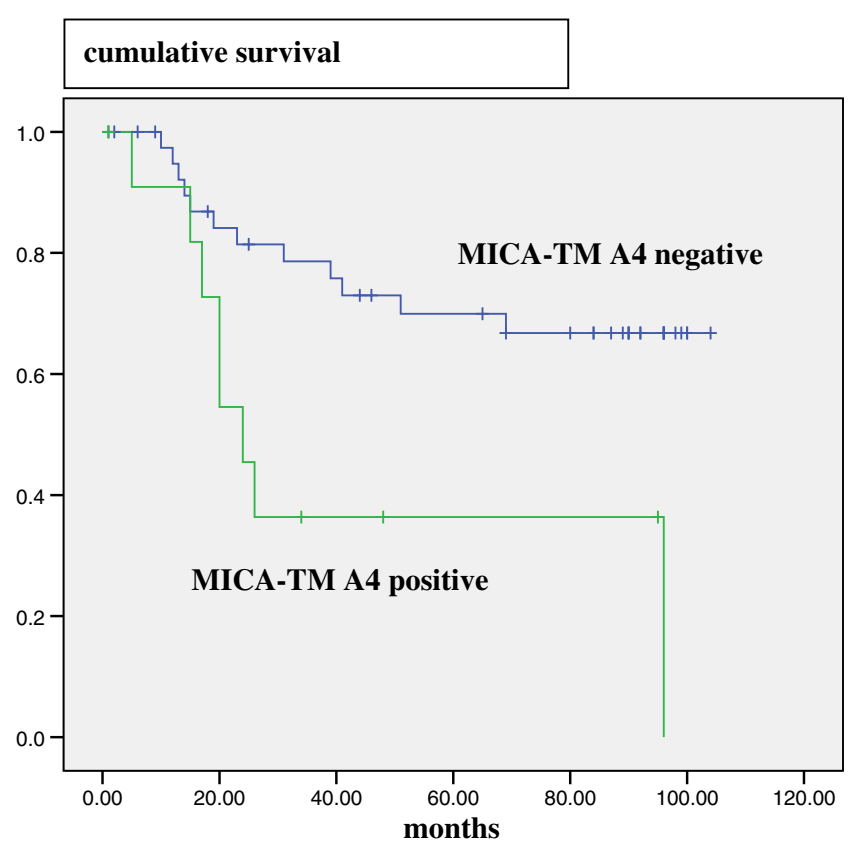

Fig. 2 MICA-TM A4 allele detection in microsatellite stable colorectal cancer patients. Kaplan-Meier analysis of tumor-related survival times in association with MICA-TM A4 allele in patients with microsatellite stable colorectal cancer. Vertical lines indicate censored observations for comparison of patients without $(n=42)$ and with MICA-TM A4 allele $(n=12, p=0.006)$. The estimated 5 -year survival rate was $72 \%$ vs $38 \%$, respectively 
Table V Survival of Patients with Microsatellite Stable Colorectal Cancer
Univariate analysis of tumorrelated survival times of patients with microsatellite stable (MIN negative) colorectal cancer and selected MICA-TM (A4, A5, A5,1, A9) and MICB C1_2_A (CA24) alleles in association with indicated clinicopathological parameters $(n=54)$. KaplanMeier analysis and the log rank test were used for comparisons and statistical evaluation

\begin{tabular}{|c|c|c|c|}
\hline Tumor-related parameters & Survival times (mean $\pm \mathrm{SD}$; months) & (95\% Confidence interval) & $p$ value \\
\hline \multicolumn{4}{|l|}{ Tumor invasion } \\
\hline $\mathrm{T} 1 / 2(n=12)$ & $81.8 \pm 11.4$ & $(59.5-104.2)$ & \multirow[t]{2}{*}{0.209} \\
\hline $\mathrm{T} 3 / 4(n=42)$ & $67.4 \pm 5.8$ & $(54.5-80.3)$ & \\
\hline \multicolumn{4}{|l|}{ Lymph node involvement } \\
\hline N negative $(n=28)$ & $89.9 \pm 6.0$ & $(78.1-101.7)$ & \multirow[t]{2}{*}{0.001} \\
\hline $\mathrm{N}$ positive $(n=26)$ & $48.6 \pm 7.9$ & $(33.1-64.1)$ & \\
\hline \multicolumn{4}{|l|}{ UICC stages } \\
\hline UICC I/II $(n=24)$ & $96.7 \pm 4.9$ & $(87.0-106.4)$ & \multirow[t]{2}{*}{$<0.001$} \\
\hline UICC III/IV $(n=30)$ & $50.8 \pm 7.3$ & $(36.4-65.23)$ & \\
\hline \multicolumn{4}{|l|}{ Distant metastasis } \\
\hline M0 $(n=38)$ & $86.7 \pm 5.4$ & $(76.0-97.4)$ & \multirow[t]{2}{*}{$<0.001$} \\
\hline M1 $(n=16)$ & $38.0 \pm 9.5$ & $(19.4-65.7)$ & \\
\hline \multicolumn{4}{|l|}{ A4 } \\
\hline No $(n=42)$ & $79.1 \pm 6.0$ & $(67.2-91.0)$ & \multirow[t]{2}{*}{0.006} \\
\hline Yes $(n=12)$ & $46.4 \pm 12.1$ & $(22.5-70.3)$ & \\
\hline \multicolumn{4}{|l|}{ A5 } \\
\hline No $(n=42)$ & $65.3 \pm 6.6$ & $(52.4-78.3)$ & \multirow[t]{2}{*}{0.042} \\
\hline Yes $(n=12)$ & $88.4 \pm 7.1$ & $(74.3-102.5)$ & \\
\hline \multicolumn{4}{|l|}{ A5.1 } \\
\hline No $(n=16)$ & $62.7 \pm 10.89$ & $(41.4-84.1)$ & \multirow[t]{2}{*}{0.236} \\
\hline Yes $(n=38)$ & $73.3 \pm 6.3$ & $(60.9-85.8)$ & \\
\hline \multicolumn{4}{|l|}{ A9 } \\
\hline No $(n=43)$ & $75.7 \pm 6.0$ & $(63.8-87.6)$ & \multirow[t]{2}{*}{0.034} \\
\hline Yes $(n=11)$ & $51.4 \pm 10.9$ & $(30.0-72.8)$ & \\
\hline \multicolumn{4}{|l|}{$\mathrm{CA} 24$} \\
\hline No $(n=37)$ & $64.8 \pm 6.6$ & $(51.7-77.9)$ & \multirow[t]{2}{*}{0.156} \\
\hline Yes $(n=11)$ & $81.9 \pm 9.5$ & $(63.2-100.6)$ & \\
\hline \multicolumn{4}{|l|}{ KRAS codon 12 mutations } \\
\hline No $(n=39)$ & $77.2 \pm 6.5$ & $(64.4-90.0)$ & \multirow[t]{2}{*}{0.121} \\
\hline Yes $(n=15)$ & $54.5 \pm 10.5$ & $(33.9-75.1)$ & \\
\hline
\end{tabular}

MICA complex by protein expression, crystallization, and crystallography showed the interaction of a NKG2D homodimer with a single MICA monomer either at the alpha 1 or alpha 2 domain forming a relatively stable Interaction, more stable than other T-cell receptor-ligand or other NK cell surface receptor-ligand complexes [25]. Groh et al. have shown an increased tumor antigen cross-presentation and priming of antitumor $\mathrm{CD} 8$ and $\mathrm{CD} 4 \mathrm{~T}$-cell responses by loading of dendritic cells with MICA antibodies following coculture with various tumor cells [21]. Recent studies investigating mRNA expression on various benign and malignant tissues and samples from patients with autoimmune diseases have shown a more widely distribution of MICA and MICB expression independent of malignancies or inflammation with the only exception for the central nervous system [26]. So far, it remains unclear whether a different genomic composition of MICA alleles might alter the ligand affinity of MICA alleles to NKG2D receptors and thereby modulate the host antitumor response.

In our study, we observed a significant association of MICA-TM A4 allele with advanced tumor progression and reduced tumor-related survival times. In contrast, patients with the MICA-TM A5 allele had a remarkably low rate of tumor lymph node invasion and less distant metastases. Furthermore, in microsatellite stable tumors, genomic MICA-TM A4 and A9 alleles were related to advanced tumor progression and shorter tumor-related survival, while the MICA-TM A5 allele was again found to have a tumor suppressive effect. These findings first indicate a host imminent predisposition with an altered tumor immune surveillance probably mediated by a differential composition of host MICA-TM alleles in patients with colorectal cancer.

At present, the there is no evidence that the MICA-TM microsatellite polymorphism directly affects NKG2D interaction or shedding of MICA molecules. Interestingly, the MICA-TM A4 and A9 alleles share methionine, M, at amino acid position 129, whereas the A5 alleles always code for valine, $\mathrm{V}$, at this position (IMGT/HLA Database). The MICA-TM alleles 5.1 and 6 do not form a haplogroup with this polymorphic residue and can possess either $\mathrm{M}$ or $\mathrm{V}$ at amino acid position 129. Steinle et al. [5] have shown 


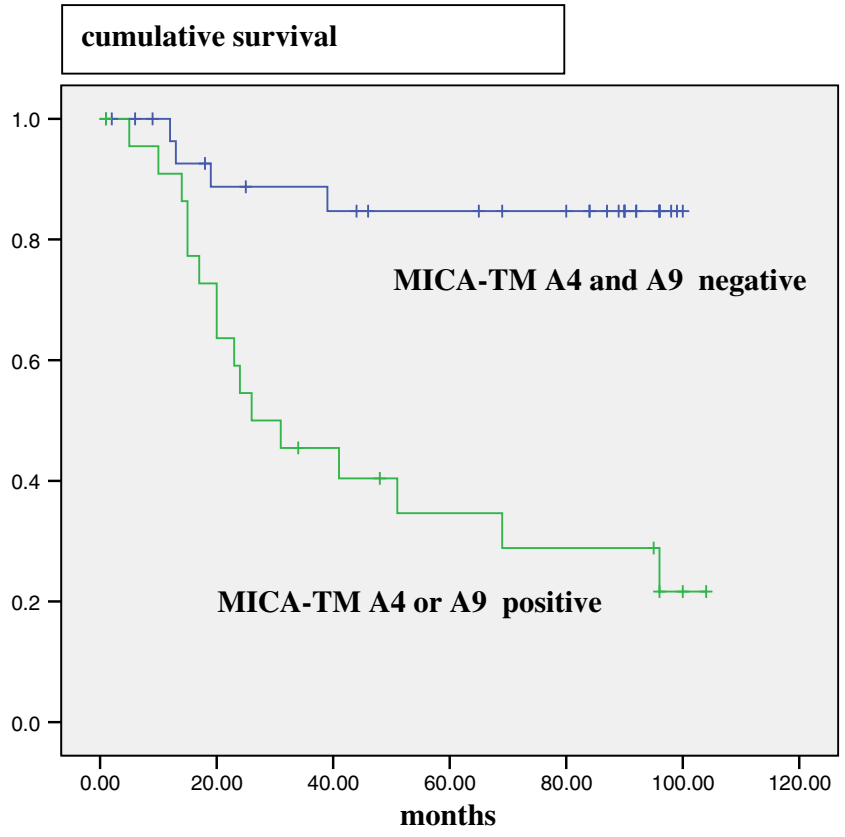

Fig. 3 MICA-TM A4 or A9 haplotype in microsatellite stable colorectal cancer patients. Kaplan-Meier analysis of tumor-related survival times in association with MICA-TM A4 or A9 alleles in patients with microsatellite stable colorectal cancer. Vertical lines indicate censored observations for comparison of patients either positive for MICA-TM A4 or A9 alleles $(n=23)$ in comparison to patients without MICA-TM A4 and A9 alleles $(n=31, p \leq 0.001)$

that MICA V129 is associated with reduced affinity for NKG2D, whereas M129 confers high NKG2D binding affinity to NKG2D receptors involving the amino acid position M129 might be responsible for the described association with advanced tumor progression and reduced tumor-related survival time. Thus, shedded MICA M129 might more powerfully impair NK and CD8 T-cell responses in vivo and/or downregulate NKG2D expression on effector cells. But, surface MICA M129 might also directly control its pronounced downregulation upon interaction with a strong-affinity MICA protein.

In other epithelial tumors, Lo et al. have described an association of the MICA-TM A9 allele with gastric cancer and a less schirrous phenotype [27]. The relevance of the NKG2D-ligand immune response in gastric cancer is further supported by Osaki et al. describing a decreased NKG2D expression on CD8+ T cell in patients with gastric cancer [28]. Busche et al. have shown a reduced staining of MICA on the surface of lung cancer samples [29]. In addition, the authors demonstrated in an experimental human lung cancer therapy model that an upregulation of MICA expression in lung cancer cells by adenoviral transfection of expression plasmids was able to reestablish the previously decreased NK cell-mediated antitumor immunity. In thyroid carcinomas, MICA and MICB expression was detected by immunohistochemistry on most tumor samples and on thyroid cancer cell lines with a correlation of their sensitivity to killing by NKG2Dpositive NK cells. Transient transfection of mutant BRAF and KRAS oncogenes led to increased MICA and MICB expression in thyroid cancer cells [30]. As shown in our analysis, we only observed a trend for an association of the MICB C1_2_A CA23 allele $(p=0.087)$ with the detection of KRAS mutations in colorectal cancer samples.

Differential expression of MICA molecules locally present at the surface of tumor cells might additionally regulate local tumor-immune interactions. We therefore cannot rule out that alterations of MICA or MICB at the level of transcription or protein synthesis might result in different levels of MICA and MICB protein expression on the surface of tumor cells. Therefore, the investigation of MICA and MICB alleles at protein expression level on the individual tumor samples will be of further interest. Several studies using immunohistochemistry have shown a reduced expression of MICA at the protein level on tumor cells [27, 29]. It is unclear whether the reduction in MICA protein expression on tumor cells is caused by reduced MICA synthesis or is the result of an increased shedding of MICA molecules in cancer patients.

The factors involved in shedding of soluble MICA molecules from tumor cells are only poorly understood. It is assumed that metalloproteinases are involved in proteolytic cleavage of soluble MICA molecules from the surface of tumor cells, leading to inactivation of NKG2D mediated antitumor response [31]. Elevated levels of soluble MICA levels were described for patients with gastrointestinal cancer [9]. Interestingly, the authors also report an association of MICA levels with advanced staged of tumor progression especially in patients with gastrointestinal renal, prostate, and breast cancer with highest levels in patients with metastatic disease. It is assumed that the reduction of MICA expression by release and shedding from the cell surface would potentially reduce the immunogenetic signals of tumor cells becoming less detectable for $\mathrm{NK}$ and $\mathrm{T}$ cells. These findings further support the concept that the NKG2D/ligand system seems to play an important role in the immune surveillance of tumor cells. However, it remains to be determined if any of the described MICA alleles might be related to differential shedding of soluble MICA molecules and thereby influence antitumor immunity and tumor progression.

Elevated antibodies against MICA were recently described in tumor patients and in recipients of renal and heart transplants with differential responses to immune therapy or an increased rejection rate associated with a reduced graft survival [32-34]. It is assumed that MICA antibodies are able to opsonize cancer cells for presentation to dendritic cells and induce tumor cell lysis through complement fixation. In addition, genetic modifications of human T cells 
with chimeric NKG2D receptors might further increase innate antitumor response [35].

In summary, these findings might indicate a host innate immunogenetic antitumor surveillance associated with advanced colorectal tumor progression and reduced tumorrelated survival based on the presence of specific MICATM alleles involved in NKG2D-receptor activation.

Open Access This article is distributed under the terms of the Creative Commons Attribution Noncommercial License which permits any noncommercial use, distribution, and reproduction in any medium, provided the original author(s) and source are credited.

\section{References}

1. Bahram S, Breshnahan M, Geraghty DE, Spies T. A second lineage of mammalian major histocompatibility complex class I gene. Proc Natl Acad Sci U S A. 1994;91:6259-63. doi:10.1073/ pnas.91.14.6259.

2. Bauer S, Groh V, Wu J, Steinle A, Phillips JH, Lnier LL, et al. Activation of NK cells and T cells by NKG2D, a receptor for stress-inducible MICA. Science. 1999;285:727-9. doi:10.1126/ science.285.5428.727.

3. Diefenbach A, Jensen ER, Jamieson AM, Raulet DH. Rae1 and H60 ligands of the NKG2D receptor stimulate tumour immunity. Nature. 2001;413(6852):165-71. doi:10.1038/35093109.

4. Raulet DH. Roles of the NKG2D immunoreceptor and its ligand. Nat Rev Immunol. 2003;3:781-90. doi:10.1038/nri1199.

5. Steinle A, Li P, Morris DL, et al. Interactions of human NKG2D with its ligands MICA, MICB, and homologs of the mouse RAE-1 protein family. Immunogen. 2001;53:279-87. doi:10.1007/s002510100325.

6. Bahram S, Mizuki N, Inoko H, Spiess T. Nucleotide sequence of the human MHC class I MICA gene. Immunogen. 1996;44:80101. doi:10.1007/BF02602661.

7. Zhang Y, Lazaro AM, Lavingia B, Stastny P. Typing of all known MICA alleles by group-specific PCR and SSOP. Hum Immunol. 2001;62:620-31. doi:10.1016/S0198-8859(01)00241-5.

8. Lenguel CS, Willis LJ, Mann B, Baker D, Kortemme T, Strong $\mathrm{RK}$, et al. Mutations designed to destabilize the receptor-bound conformation increase MICA-NKG2D association rate and affinity. J Biol Chem. 2007;282(42):30658-66. doi:10.1074/jbc. M704513200.

9. Holdenrieder S, Stieber P, Peterfi A, Nagel D, Steinle A, Salih HR. Soluble MICA in malignant diseases. Int J Cancer. 2006;118 (3):684-7. doi:10.1002/ijc.21382.

10. Groh V, Wu J, Yee C, Spiess T. Tumour-derived soluble MIC ligands impair expression of NKG2D and T-cell activation. Nature. 2002;419(6908):734-7388. doi:10.1038/nature01112.

11. Kato N, Tanaka J, Sugita J, Toubi T, Miura Y, Ibata M, et al. Regulation of the expression of MHC class I-related chain A, B (MICA, MICB) via chromatin remodeling and its impact on the susceptibility of leukemic cells to the cytotoxicity of NKG2Dexpressing cells. Leukemia. 2007;21(10):2103-8. doi:10.1038/sj. leu. 2404862.

12. Gambelunghe G, Falorni A, Ghaderi M, Laureti S, Tortoioli C, Santeusiano F, et al. Microsatellite polymorphism of the MHC class I chain-related (MIC-A and MIC-B) genes marks the risk for autoimmune Addison's disease. J Clin Endocrinol Metab. 1999;84 (10):3701-7. doi:10.1210/jc.84.10.3701.

13. Ostberg JR, Dayanc BE, Yuan M, Oflazoglu E, Repasky EA. Enhancement of natural killer (NK) cell cytotoxicity by fever-range thermal stress is dependent on NKG2D function and is associated with plasma membrane NKG2D clustering and increased expression of MICA on target cells. J Leukoc Biol. 2007;82(5):1322-31. doi:10.1189/jlb.1106699.

14. Wrobel P, Shojaei H, Schittek B, Gieseler F, Wollenberg B, Kalthoff $\mathrm{H}$, et al. Lysis of a broad range of epithelial tumour cells by human gamma delta $\mathrm{T}$ cells: involvement of NKG2D ligands and T-cell receptor- versus NKG2D-dependent recognition. Scand J Immunol. 2007;66(2-3):320-8. doi:10.1111/j.1365-3083.2007.01963.x.

15. Mizuki N, Ota M, Kimura M, Ohno S, Ando H, Katsuyma M, et al. Triplet repeat polymorphism in the transmembrane region of the MICA gene: a strong association of six GCT repetitions with Behcet disease. Proc Natl Acad Sci U S A. 1997;94(4):1298-303. doi:10.1073/pnas.94.4.1298.

16. Boland CR, Thibodeau SN, Hamilton SR, Sidransky D, Eshleman $\mathrm{JR}$, Burt RW, et al. A national cancer institute workshop on microsatellite instability for cancer detection and familial predisposition: development of international criteria for the determination of microsatellite instability in colorectal cancer. Cancer Res. 1998;58:5248-57.

17. Glas J, Werner AI, Brunnler G, Witter K, Scholz S, Weiss EH, et al. Linkage disequilibria between HLA-B, C1_4_1, MICA and MICB. Tissue Antigens. 2001;58(6):411-8. do $\bar{i}: 10.1034 / j .1399$ 0039.2001.580611.x.

18. Glas J, Martin K, Brunnler G, Kopp R, Folwaczny C, Weiss EH, et al. MICA, MICB and C1_4_1 polymorphism in Crohn's disease and ulcerative colitis. Tissue Antigens. 2001;58(4):243-9. doi:10.1034/j.1399-0039.2001.580404.x.

19. Rincon-Orozco B, Kunzmann V, Wrobel P, Kabelitz D, Steinle A, Herrmann T. Activation of $\mathrm{V}$ gamma $9 \mathrm{~V}$ delta $2 \mathrm{~T}$ cells by NKG2D. J Immunol. 2005;175(4):2144-51.

20. Poggi A, Prevesto C, Zancolli M, Canevali P, Musso A, Zocchi MR. NKG2D and natural cytotoxicity receptors are involved in natural killer cell interaction with self-antigen presenting cells and stromal cells. Ann N Y Acad Sci. 2007;1109:47-57. doi:10.1196/ annals.1398.007.

21. Groh V, Li YQ, Cioca D, Wang W, Riddell SR, Yee C, et al. Efficient cross-priming of tumor antigen-specific $\mathrm{T}$ cells by dendritic cells sensitized with diverse anti-MICA opsonised cells. Proc Natl Acad Sci U S A. 2005;102(18):6461-6. doi:10.1073/ pnas.0501953102.

22. Bouet-Toussaint F, Cabillic F, Toutiris O, Le Gallo M, Thomas de la Pintiere C, Daniel P, et al. Vgamma9Vdelta2 T cell-mediated recognition of human solid tumors. Potential for immunotherapy of hepatocellular and colorectal carcinomas. Cancer Immunol Immunother. 2007;57(4):531-9. doi:10.1007/s00262-007-0391-3.

23. Germain C, Larbouret C, Cesson V, Donda A, Held W, Mach JP, et al. MHC class I-related chain A conjugated to antitumor antibodies can sensitize tumor cells to specific lysis by natural killer cells. Clin Cancer Res. 2005;11(20):7516-22. doi:10.1158/ 1078-0432.CCR-05-0872.

24. Beetz S, Marischen L, Kabelitz D, Wesch D. Human gamma delta T cells: candidates for the development of immunotherapeutic strategies. Immunol Res. 2007;37(2):97-111. doi:10.1007/BF02685893.

25. Li P, Morris DL, Willcox BE, et al. Complex structure of the activating immunoreceptor NKG2D and its MHC class I-like ligand MICA. Nat Immunol. 2001;2(5):443-51.

26. Schrambach S, Ardizone M, Leymarie V, Sibilla J, Bahram S. In vivo expression pattern of MICA and MICB and its relevance to autoimmunity and cancer. PLoS One. 2007;2(6):e518. doi:10.1371/ journal.pone.0000518.

27. Lo SS, Lee YJ, Wu CW, Liu CJ, Huang JW, Lui WY. The increase of MICA gene A9 allele associated with gastric cancer and less schirrous change. Br J Cancer. 2004;90(9):1809-13.

28. Osaki T, Saito H, Yoshikawa T, Matsumoto S, Tatebe Tsujitani S, Ikeguchi M. Decreased NKG2D expression on CD8 $+\mathrm{T}$ cell is 
involved in immune evasion in patients with gastric cancer. Clin Cancer Res. 2007;13(2 Pt 1):382-7. doi:10.1158/1078-0432.CCR06-1454.

29. Busche A, Goldmann T, Maumann U, et al. Natural killer cellmediated rejection of experimental human lung cancer by genetic overexpression of major histocompatibility complex class I chainrelated gene A. Hum Gene Ther. 2006;17(2):135-46. doi:10.1089/ hum.2006.17.135.

30. Xu X, Rao G, Gaffud MJ, Ding HJ, Maki G, Klingemann HG, et al. Clinicopathological significance of major histocompatibility complex class I-related chain a and B expression in thyroid cancer. J Clin Endocrinol Metab. 2006;91(7):2704-12. doi:10.1210/jc.2006-0492.

31. Salih HR, Pammensee HG, Steinle A. Cutting edge: downregulation of MICA on human tumors by proteolytic shedding. J Immunol. 2002;169(8):4098-102.
32. Jinushi M, Hodi FS, Dranoff G. Therapy-induced antibodies to MHC class I chain-related protein A antagonize immune suppression and stimulate antitumor cytotoxicity. Proc Natl Acad Sci U S A. 2006;103(24):9190-5. doi:10.1073/pnas.0603503103.

33. Zou Y, Stastny P, Susal C, Dohler B, Opelz G. Antibodies against MICA antigens and kidney-transplant rejection. N Engl J Med. 2007;357(13):1293-300. doi:10.1056/NEJMoa067160.

34. Suarez-Alvarez B, Lopez-Vaquez A, Gonzales MZ, et al. The relationship of anti-MICA antibodies and MICA expression with heart allograft rejection. Am J Transplant. 2007;7(7):1842-8. doi:10.1111/j.1600-6143.2007.01838.x.

35. Zhang T, Barber A, Sentman CL. Generation of antitumor responses by genetic modification of primary human $\mathrm{T}$ cells with a chimeric NKG2D receptor. Cancer Res. 2006;66(11):5927-33. doi:10.1158/ 0008-5472.CAN-06-0130. 